\title{
Ekstraksi Click Stream Data Web E-Commerce Menggunakan Web Usage Mining
}

\author{
Kartina Diah ${ }^{1}$ \\ ${ }^{1,2}{ }^{1}$ Jurusan Teknologi Informasi, Program Studi Teknik Informatika, Politeknik Caltex Riau \\ ${ }^{1}$ diah@pcr.ac.id
}

\begin{abstract}
Abstrak
E-Commerce berkembang pesat dalam world wide web hingga menghasilkan berbagai jenis data yang dapat dianalisa lebih lanjut untuk berbagai keperluan seperti personifikasi web, profiling customer, dan sebagainya. Salah satu jenis data yang dihasilkan e-Commerce adalah click stream data web yang merekam aktivitas visitor web dalam bentuk log data selama berinteraksi pada laman web. Penelitian ini mengekstraksi click stream data web e-commerce untuk mendapatkan pola interaksi konsumen terhadap halaman web selama mengunjungi web e-commerce. Berdasarkan jenis data yang diekstrak maka web usage mining digunakan untuk ekstraksi pola dari click stream data yang berbentuk log data. Teknik mining yang dianalisa terhadap log data e-commerce pada penelitian ini terdiri dari frequent itemset, asociation rules, dan frequence sequence mining. Frequent itemset menghasilkan halaman web yang paling sering diakses oleh visitor. Association rules menghasilkan pola kemungkinan halaman web yang akan diakses visitor jika visitor mengakses halaman-halamn tertentu. Frequence sequence mining mendapatkan pola urutan halaman web yang paling sering diakses oleh visitor web e-commerce saat berinteraksi pada laman web. Pola urutan halaman yang diakses visitor menunjukkan urutan kebiasaan visitor mengunjungi e-commerce. Sedangkan teknik mining yang diimplementasikan untuk menghasilkan pola akses visitor pada penelitian ini adalah Frequence sequence mining. Hasil ekstraksi dari penelitian ini menunjukkan ada enam halaman web yang paling sering diakses oleh konsumen dengan berbagai pola urutan aksesnya.
\end{abstract}

Kata kunci : e-commerce, web usage mining, click stream data, frequence sequence

\section{Pendahuluan [Times New Roman 10, bold]}

Aplikasi electronic commerce atau $e$-commerce adalah aplikasi enterprise berbasis web yang dewasa ini semakin berkembang seiring pesatnya perkembangan world wide web. Dengan $e$ commerce seorang kostumer dapat memanfaatkan fasilitas web untuk berbelanja berbagai kebutuhan barang maupun jasa dari penjual barang dan jasa yang ada diberbagai tempat diseluruh worldwide(Tatsiopoulos et al., 2002).

$E$-Commerce didefinisikan sebagai kegiatan jual beli produk, layanan, dan informasi melalui jaringan komputer khususnya internet (Wen et al., 2001). Lebih jauh disebutkan bahwa $e$-commerce tidak terbatas hanyapada aktivitas jual-beli saja, tetapi mencakup berbagai proses yang dilakukan dalam organisasi yang mendukung tujuan dari bisnisnya (Diah \& Yunanto, 2017).

Data web yang merekam aktivitas visitor web disebut sebagai data click stream. Data click stream pada aplikasi e-commerce dapat terdiri dari data access logs, browser logs, user profiles, registration data, user session, cookies, dan data lainnya yang merupakan hasil transaksi user dengan web. Dari data tersebut banyak informasi yang dapat dihasilkan bagi web site management. Selain menemukan web site yang paling sering dikunjungi pengguna, dapat juga diidentifikasi web site mana yang kemungkinan akan dikunjungi bersamaan oleh user serta kebiasaan pengguna pada saat mengunjungi sebuah web. Salah satu teknologi yang dapat digunakan untuk mengolah dan menggali pengetahuan dari data dalam jumlah besar dengan tipe data yang bervariasi adalah data mining. Sedangkan metode data mining yang digunakan untuk mengekstrak pengetahuan yang berasal dari data web disebut sebagai web mining (Cooley, 2000). Srivastava,dkk dalam "Web Mining Concept, Application, and Research Direction" menyebutkan, ada dua pendekatan yang dapat digunakan untuk mendefinisikan web mining. Pertama, pendekatan berbasis proses (processcentric-view) yang mendefinisikan web mining sebagai urutan aktivitas (sequence of task). Kedua, pendekatan berbasis data (data-centric view) yang mendefinisikan web mining sebagai terminology tipe data web yang digunakan untuk proses data mining.(Abdurrahman et al., 2008;Srivastava \& Desikan, Prasanna, Kumar, n.d.;Cooley et al., 1997).

WUM adalah aplikasi teknik data mining untuk menemukan pola penggunaan dari data web dengan tujuan memahami dan memberikan layanan yang lebih baik pada aplikasi berbasis web(Cooley, 2000; 
Wang, 2000). Dalam penelitian (Senkul, Pinar, 2012), web usage mining juga digunakan untuk memberikan halaman rekomendasi bagi pelanggan web e-commerce berdasarkan profil pelanggan yang diperoleh dari data log. Penelitian(Mishra, 2012) melakukan ekstraksi terhadap data log web untuk mendapatkan pola akses pengunjung web yang paling frequent menggunakan algoritma FP-Growth. Mining data log web menggunakan klasifikasi juga digunakan dalam (Azam, \& Tabrez, 2014) untuk mengetahui pola kunjungan pelanggan yang berasal dari dalam India dan pola kunjungan pelanggan yang berasal dari luar India. Association rule dalam penelitian (Wani, K., \& Bakal, 2014) juga digunakan untuk mendapatkan pola kunjungan pelanggan serta mengetahui hubungan antara halaman yang dikunjungi untuk dapat memberikan rekomendasi halaman yang tepat bagi pelanggan.

Dari latar belakang yang diuraikan penulis diatas maka tujuan dari penelitian ini adalah menghasilkan ekstraksi data click stream dari aplikasi e-commerce menggunakan teknologi web usage mining.

\section{Tinjauan Pustaka}

\section{$>$ Web Usage Mining}

Berdasarkan jenis data yang diekstrak, web mining dapat dibagi menjadi tiga kategori, yaitu (Diah \& Yunanto, 2017; Hamid Mughal, 2018; Srivastava et al., 2005; Roy \& Appa Rao, 2020; Iváncsy \& Vajk, 2006):

1. Web Content Mining (WCM); teknik data mining untuk menghasilkan informasi tentang content sebuah dokumen web. Dokumen web tersebut dapat berupa teks, gambar, audio, video, structured records seperti list dan table.

2. Web Structure Mining (WSM); teknik data mining untuk menghasilkan informasi tentang struktur web. Terbagi menjadi 2, yaitu hyperlinks, document structure.

3. Web Usage Mining (WUM) (sedikit ulasan ttg WCM); teknik data mining yang digunakan untuk menemukan pola penggunaan web dari web usage data, dengan tujuan untuk memahami dan memberikan layanan yang lebih baik pada aplikasi berbasis web (Srivastava et al., 2000). Pola yang dihasilkan berasal dari klasifikasi usage data sebagai berikut, web server data, application server data, application level data.

Langkah-langkah yang dilakukan dalam WUM terbagi menjadi 3 tahap, yaitu (Diah \& Yunanto, 2017;Rathod, 2012;Cooley, 2000; Vellingiri, J;Pandian, 2011):

1. Pre-processing. Data yang tersedia memiliki kecendrungan mengandung noise, tidak lengkap dan tidak konsisten. Pada tahap ini, data akan diolah untuk disesuaikan dengan kebutuhan pada fase berikutnya. Tahap ini meliputi pembersihan data, integrasi data, transformasi data dan reduksi data.
2. Pattern discovery. Beberapa metode dan algoritma seperti statistic, data mining, machine learning, dan pattern recognition dapat diterapkan untuk mendapatkan pola pada tahap ini.

Proses "mining" terjadi pada tahapan ini, meliputi (Cooley dkk.,2000; Wang, 2000)): statistical analysis, association rules, clustering, classification, frequent pattern, sequential pattern, dependency modeling .

3. Pattern Analysis. Pola yang telah ditemukan selanjutnya dianalisa dan ditampilkan dengan visualisasi dan interpretasi yang lebih difahami oleh pengguna.

\section{Data Web Log}

Untuk melakukan analisis terhadap $\log w e b$, pertama-tama adalah dengan membagi data log web ke sesi, di mana sesi adalah serangkaian referensi halaman satu situs web selama satu periode logis. Sesi didefinisikan sebagai periode browsing web berkelanjutan atau urutan tampilan halaman web. Sesi juga dapat dilihat sebagai awal pengguna mengunjungi situs web, melakukan pekerjaan, dan kemudian meninggalkan situs web (Sun \& Zhang, 2004).

Ratnes Kumar Jain dan kawan-kawan dalam (Jain \& Kasana, 2009) menyatakan bahwa log file berisi informasi sebagai berikut (Grace \& Nagamalai, 2011):

1. Visited path: path yang terekam oleh log ketika pengguna mengakses halamanhalaman web.

2. Username: dibeberapa website pengguna diminta untuk mengisikan nama sebelum mengakses website. Selain itu, identitas pengguna juga dapat diidentifikasi dari IP Address yang tercatat pada log setiap pengguna mengakses website.

3. Path traversed: mengidentifikasi path-path yang dilalui oleh pengguna

4. Timestamp: durasi pengguna mengakses website.

5. Page last visited: halaman terakhir yang diakses oleh pengguna

6. Success rate: tingkat keberhasilan diukur dari banyaknya jumlah data yang diunduh oleh pengguna

7. User agent: web browser yang digunakan oleh pengguna untuk mengakses website

8. URL: alamat sumber yang diakses oleh pengguna

9. Request type: method yang digunakan untuk transfer data, misalnya POST atau GET. 


\section{Analisis Penerapan Web Usage Mining pada Data Click Stream \\ 3.1 Metodologi Penelitian}

Penelitian ini terdiri dari beberapa tahap yaitu data collection, data preprocessing, data exploration, data visualization. Tahapan-tahapan tersebut digambarkan pada gambar 1 berikut ini.

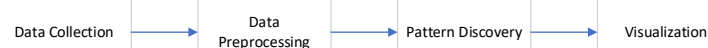

Gambar 1 Tahapan Metodologi Penelitian

- Data Collection

Data $\log$ web yang digunakan dalam penelitian ini adalah data click stream yang diunduh dari ECML/PKDD 2005 Discovery Challenge ${ }^{l}$. Setiap file $\log$ berisi informasi yang dikumpulkan selama satu jam dari 7 buah aplikasi e-commerce. Data log yang digunakan pada penelitian ini berjumlah 600.000 baris data.

\section{- Data Preprocessing}

Tidak semua data logs digunakan pada tahap mining data karena beberapa data tidak relevan dengan kebutuhan terhadap mining yang akan dilakukan, untuk itu diperlukan tahap preprocessing data terlebih dahulu. Tahapan preprocessing terdiri dari data cleaning berfungsi untuk membersihkan logs entries dari data yang tidak dibutuhkan pada proses mining. Session identification berfungsi untuk mengidentifikasi semua halaman referensi yang digunakan oleh pengguna untuk disimpan menjadi data dalam user session. Data conversion berfungsi untuk menyesuaikan format data sesuai dengan kebutuhan pada mining proses.

\section{- Pattern Discovery}

Mengimplementasikan algoritma yang tepat yang sesuai dengan kebutuhan penelitian dilakukan pada tahap ini. Pada penelitian ini algoritma yang diimplementasikan merupakan hasil analisis terhadap 3 buah algoritma yang umum digunakan pada Web Usage Minig yaitu frequent item set, association rule dan frequent sequence item set. Analisis pada tahapan ini dilakukan untuk menentukan algortima yang paling tepat agar menghasilkan sebuah pola perilaku konsumen pada saat berinteraksi menggunakan web e-commerce.

\section{- Visualization}

Pada tahapan ini akan menampilkan pola yang dihasilkan pada tahap sebelumnya dalam bentuk diagram agar pola interaksi konsumen saat menggunakan web e-commerce dapat lebih mudah digunakan lebih lanjut pada penelitian selanjutnya.

Evaluasi model yang dihasilkan pada penelitian ini baru akan dilakukan pada penelitian lanjutan yaitu mengimplementasikan model yang diperoleh menjadi sebuah web e-commerce, sehingga dapat ditentukan seberapa akurat model yang dihasilkan dapat memenuhi semua fungsional untuk sebuah aplikasi e-commerce.

\subsection{Web Usage Mining}

WUM melakukan mining untuk mengekstraksi pola yang berasal dari usage data yaitu log data. Log akses web berisi urutan kejadian atau akitivitas atau events (items) dalam satu session, dengan informasi mencakup session identifier dan informasi akses pengguna. Misalkan, dalam data log web terdiri dari informasi beberapa halaman web yang dikunjungi oleh pengunjung dalam 1 session. Sebagai contoh, format informasi dari sebuah akses log adalah <SessionId,PageId>, dan data log akses web dari beberapa session sesuai format adalah sebagai berikut:

$<100, \mathrm{a}><100, \mathrm{~b}><200, \mathrm{e}><200, \mathrm{a}><300, \mathrm{~b}><20$ $0, \mathrm{e}><100, \mathrm{~d}><200, \mathrm{~b}><400, \mathrm{a}><400, \mathrm{f}><100, \mathrm{a}><400$ , b $><300, \mathrm{a}><100, \mathrm{c}><200, \mathrm{c}><400, \mathrm{a}><200, \mathrm{a}><300$, $\mathrm{b}><200, \mathrm{c}><300, \mathrm{f}><400, \mathrm{c}><400, \mathrm{f}><400, \mathrm{c}><300$, a $><300$,e $><300$,c $>$

Sebuah session dilihat sebagai awal pengguna mengunjungi situs web, melakukan aktivitas, dan kemudian meninggalkan situs web. Aktivitas yang dimaksud dalam sebuah session tersebut adalah kegiatan mengunjungi halaman-halaman web yang ada pada situs web dalam selang waktu tertentu. Sehingga jika dalam sebuah session didefinisikan sebagai $\langle 100, a\rangle, \quad\langle 100, b\rangle, \quad\langle 100, d\rangle, \quad<100, a\rangle$, $<100$,c $>$ maka dalam sebuah session dengan Id 100 melakukan aktivitas mengunjungi halaman web a,b,d,a,c.

Selanjutnya data log tersebut dikelompokkan berdasarkan session-nya seperti yang terlihat pada table 1 Contoh Sequence Databse. Urutan log akses dalam database transaksi pada pada masing-masing baris terdiri dari ID Transaksi (TID) yang berasal dari session dan urutan akses (access sequence) yang berasal dari event. Misalkan untuk session 100, event yang dilakukan terdiri dari a,b,d,a,dan c.

Tabel 1 Contoh Sequence Database

\begin{tabular}{|l|l|}
\hline TID & Web access sequences \\
\hline 100 & abdac \\
\hline 200 & eaebcac \\
\hline 300 & babfaec \\
\hline 400 & afbacfc \\
\hline
\end{tabular}

Dari tabel 1 diatas dapat diperoleh pola urutan akses yang paling sering dilakukan oleh pengunjung. Sebagai contoh, dari data diatas diperoleh bahwa halaman yang paling sering dikunjungi oleh pengunjung adalah sebagai berikut:

halaman $\mathrm{a}=4, \mathrm{~b}=4, \mathrm{c}=4, \mathrm{~d}=1, \mathrm{e}=2, \mathrm{f}=2$. 
Sehingga diketahui bahwa setiap pengunjung pasti mengunjungi halaman a, b, c sedangkan halaman $\mathrm{d}$, e, $\mathrm{f}$ ada yang mengunjungi ada yang tidak. Selanjutnya dapat juga diketahui pola urutan halaman yang paling sering dikunjungi oleh pengunjung yaitu a,b,a,c. Artinya setiap pengunjung akan mengunjungi halaman web dengan urutan halaman a diikuti halaman $b$ kemudian kembali ke halaman a lalu ke halaman c. Urutan halaman yang dikunjungi tersebut jika digambarkan dalam sebuah graph maka akan terlihat pada gambar 1 sebagai berikut:

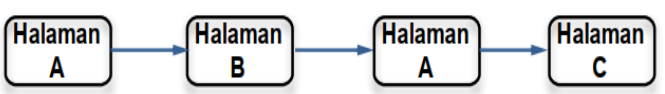

Gambar 2 Urutan Kunjungan Halaman Web Dengan WUM

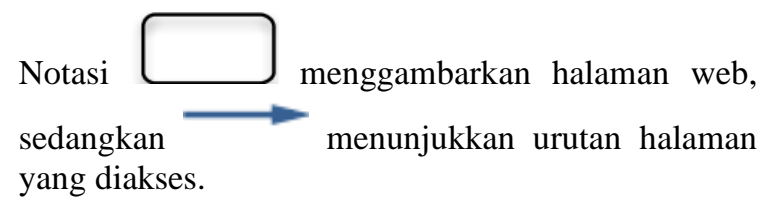

\subsection{Pendekatan Teknik WUM untuk Pattern Discovery}

\section{Frequent Itemset}

Frequent Pattern adalah teknik mining yang dilakukan dengan menganalisa jumlah itemset yang kemunculannya melebihi nilai support-nya. Berdasarkan contoh yang diberikan pada lampiran B tentang frequent itemset, maka dihasilkan pola akses halaman web seperti pada gambar 2 Pola Akses Halaman Web Dengan Frequent Itemset dibawah ini.

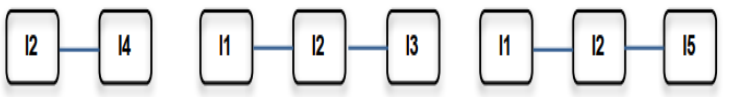

Gambar 3 Pola Akses Halaman Web Dengan Frequent Itemset

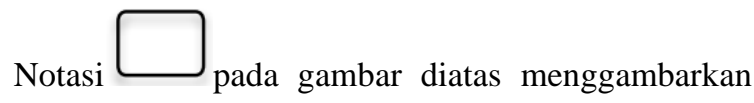

halaman web, sedangkan menggambarkan halaman yang diakses dengan mengabaikan urutan. Dari analisa yang telah dilakukan diketahui bahwa frequent itemset mining menghasilkan sebuah model dari itemset yang paling sering dikunjungi oleh pengunjung dalam 1 session. Dalam frequent itemset mining tidak menunjukkan informasi temporal yang menggambarkan sebuah urutan akses halaman web dari waktu ke waktu secara runut.

\section{Association rules}

Association rules atau aturan asosiasi adalah teknik mining yag digunakan untuk menemukan hubungan antara atribut dalam sebuah itemset. Di dalam data $\log$ web itemset adalah sekumpulan set halaman-halaman web dalam satu session. Aturan diterapkan untuk menunjukkan hubungan kemungkinan halaman-halaman web yang sering diakses bersama-sama setiap kali pengunjung mengunjungi web. Berdasarkan hasil confidence yang berasal dari tabel B-5 maka aturan asosiasi yang memenuhi minimum support $30 \%$ dan minimum confidence $70 \%$ adalah R2, R3, R6. Aturan asosiasi yang terbentuk menjadi,

- R2: I1 $\wedge$ I5 $\rightarrow$ I2, seorang pengunjung yang mengunjungi halaman halaman I1 dan I5 punya kemungkinan $70 \%$ untuk mengunjungi halaman I2 dengan jumlah pola kunjungan tersebut selama ini adalah $30 \%$.

- R3: I2 ^ I5 $\rightarrow$ I1, seorang pengunjung yang mengunjungi halaman halaman I2 dan I5 punya kemungkinan $70 \%$ untuk mengunjungi halaman I1 dengan jumlah pola kunjungan tersebut selama ini adalah $30 \%$.

- R6: I5 $\rightarrow$ I1 $\wedge$ I2, seorang pengunjung yang mengunjungi halaman halaman I5 punya kemungkinan $70 \%$ untuk mengunjungi halaman I2 dan I2 dengan jumlah pola kunjungan tersebut selama ini adalah $30 \%$.

Maka pola yang dihasilkan dari aturan asosiasi diatas adalah seperti gambar 3 Pola Akses Halaman Web Menggunakan Association Rule berikut.

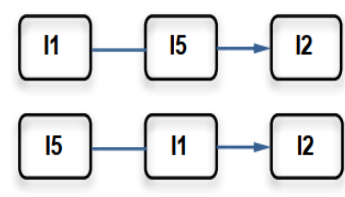

R2 : $11 \wedge 15 \rightarrow 12$

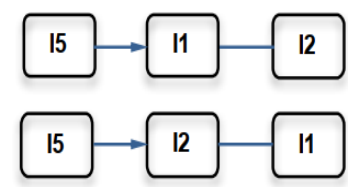

$R 6: 15 \rightarrow 11 \wedge 12$
Gambar 4 Pola Akses Halaman Web Menggunakan Association Rule

Notasi $\longrightarrow$ menggambarkan kemungkinan sebuah halaman diakses jika halaman sebelum notasi diakses oleh pengunjung, sedangkan notasi menggambarkan halaman yang diakses bersamaan.

Berdasarkan aturan asosasi yang dihasilkan diketahui bahwa satu halaman web yang dikunjungi saling mempengaruhi kemungkinan halaman web yang lain dikunjungi juga. Namun urutan kunjungan terhadap halaman web tersebut bukanlah menjadi hal yang dipertimbangkan, seperti misalkan aturan asosiasi dari R6 yang berarti setelah mengunjungi halaman I5 akan diikuti dengan mengunjungi halaman I1 lebih dulu baru halaman I2 atau sebaliknya asal kedua halaman tersebut dikunjugi setelah halaman I5 dikunjungi.

\section{Frequent Sequence Mining}

Seqeuntial Pattern pada dasarnya tersusun dari himpunan frequent itemset yang merepresentasikan 
pola berdasarkan urutan waktu terjadinya peristiwa, disebut juga dengan istilah frequent sequence.

Pola yang dihasilkan adalah pola dengan nilai maksimal diatas nilai mininum support-nya. Pola $\{(\mathrm{P} 1)(\mathrm{P} 5)\}$ tersebut berarti, secara umum pengunjung web mengakses halaman P1 kemudian mengunjungi halaman P5 diwaktu yang lain dalam rentang waktu yang sama. Begitu juga dengan pola $\{(\mathrm{P} 1), \quad(\mathrm{P} 4 \mathrm{P} 7)\}$ yang artinya, pengunjung mengunjungi halaman P1 kemudian mengunjungi halaman P4 lalu halaman P7 pada kunjungan selanjutnya dalam rentang waktu yang sama pula. Dengan demikian jika pola tersebut digambarkan dalam urutan proses maka akan terlihat seperti gambar 4 Pola Akses Halaman Web Dengan Frequence Sequence dibawah ini.

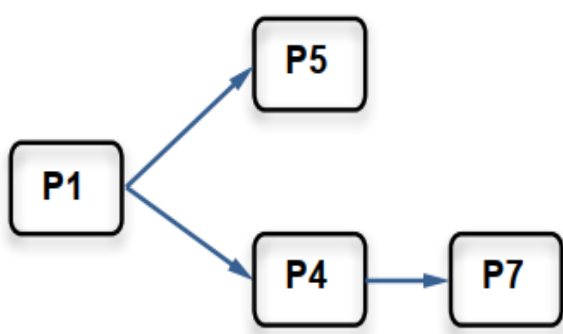

Gambar 5 Pola Akses Halaman Web Dengan Frequent Sequence

Notasi

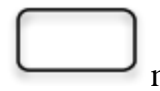
menggambarkan halaman web,

sedangkan notasi $\longrightarrow$ menunjukkan urutan halaman web yang diakses.

Berdasarkan analisis terhadap 3 algoritma diatas, hanya algoritma frequence sequence item set yang dapat menunjukkan pola urutan akses konsumen terhadap halaman web pada saat berinteraksi dengan web e-commerce. Pola urutan akses halaman web dapat dijadikan salah satu acuan dalam pengembangan aplikasi web e-commerce sehingga algoritma frequence sequence item set akan diimplementasikan pada penelitian ini.

\section{Implementasi Web Usage Mining pada Data Click Stream}

\subsection{Click Stream Data}

Data log web yang digunakan dalam penelitian ini adalah data click stream yang diunduh dari ECML/PKDD 2005 Discovery Challengel. Setiap file log berisi informasi yang dikumpulkan selama satu jam dari 7 buah aplikasi e-commerce. Data log yang digunakan pada penelitian ini berjumlah 600.000 baris data. Tabel 2 Data Log Web berikut ini adalah contoh data $\log$ dari click stream data $e$ commerce yang digunakan pada penelitian ini.
Tabel 2 Data Log Web

\begin{tabular}{|c|c|c|c|c|}
\hline $\begin{array}{c}\text { Shop } \\
\text { ID }\end{array}$ & $\begin{array}{l}\text { Unixt } \\
\text { ime() }\end{array}$ & $\begin{array}{l}\text { IP } \\
\text { Address }\end{array}$ & Session & $\begin{array}{l}\text { Visited } \\
\text { Page }\end{array}$ \\
\hline 11 & $\begin{array}{l}10746 \\
28802\end{array}$ & $\begin{array}{l}212.20 .1 \\
06.210\end{array}$ & $\begin{array}{l}\text { fadb9b66 } \\
\text { 6eab173c } \\
\text { fc090014 } \\
8 \text { ebd21c } \\
\text { b }\end{array}$ & I \\
\hline 14 & $\begin{array}{l}10746 \\
28802\end{array}$ & $\begin{array}{l}217.11 .2 \\
33.2\end{array}$ & $\begin{array}{l}8 \mathrm{a} 8 \mathrm{ad} 32 \mathrm{c} \\
814 \mathrm{ea} 45 \mathrm{c} \\
41 \mathrm{f} 1709 \mathrm{~d} \\
\mathrm{f} 7967 \mathrm{a} 19\end{array}$ & $\begin{array}{l}/ \mathrm{ct} / ? \mathrm{c}= \\
164\end{array}$ \\
\hline 11 & $\begin{array}{l}10746 \\
28802\end{array}$ & $\begin{array}{l}82.34 .18 \\
4.151\end{array}$ & $\begin{array}{l}\text { be } 5 \text { d5d6 } \\
\text { dc24bf3e } \\
54530 d 7 \\
\text { dc } 8945 f f \\
25\end{array}$ & $\begin{array}{l}\text { lznacka } \\
/ ? \& \text { poz } \\
\text { ice }=10 \\
0 \& c=1 \\
02\end{array}$ \\
\hline 12 & $\begin{array}{l}10746 \\
28802\end{array}$ & $\begin{array}{l}80.188 .4 \\
42\end{array}$ & $\begin{array}{l}\text { 7a7f25ac } \\
\text { 8ed0f4e6 } \\
\text { 4a1c524 } \\
803 c 526 \\
\text { e8 }\end{array}$ & $\begin{array}{l}/ \mathrm{dt} / ? \mathrm{c}= \\
9674 \& \\
\text { koment } \\
\text { are }=1\end{array}$ \\
\hline 14 & $\begin{array}{l}10746 \\
28803\end{array}$ & $\begin{array}{l}195.250 \\
148.121\end{array}$ & $\begin{array}{l}\text { ed03ab0 } \\
9 \mathrm{cc0ac7d} \\
67 \mathrm{a} 5735 \\
599 \mathrm{bc} 6 \mathrm{~b} \\
88 \mathrm{e}\end{array}$ & $\begin{array}{l}/ \mathrm{dt} / ? \mathrm{c}= \\
7308\end{array}$ \\
\hline 11 & $\begin{array}{l}10746 \\
28805\end{array}$ & $\begin{array}{l}212.20 .9 \\
9.79\end{array}$ & $\begin{array}{l}\text { 2cbb61ae } \\
\text { fadb5fd2 } \\
5 \mathrm{f} 6 \mathrm{~d} 7 \mathrm{c} 9 \mathrm{e} \\
7 \mathrm{a} 596 \mathrm{ce} 6\end{array}$ & $\begin{array}{l}/ \mathrm{dt} / ? \mathrm{c}= \\
927\end{array}$ \\
\hline 10 & $\begin{array}{l}10746 \\
28805\end{array}$ & $\begin{array}{l}212.111 . \\
9.109\end{array}$ & $\begin{array}{l}344 \mathrm{ce} 20 \\
2 \mathrm{~b} 8094 \mathrm{~d} \\
3 \mathrm{aecf} 2 \mathrm{fff} \\
84 \mathrm{cf} 5 \mathrm{da} 3 \\
1\end{array}$ & $\begin{array}{l}\text { /znacka } \\
\text { /?\&poz } \\
\text { ice }=20 \\
\& c=2\end{array}$ \\
\hline 15 & $\begin{array}{l}10746 \\
28806\end{array}$ & $\begin{array}{l}194.108 \\
242.78\end{array}$ & $\begin{array}{l}\text { 2feff867 } \\
21 \mathrm{f} 48 \mathrm{bea} \\
10510 \mathrm{e} 1 \\
594 \mathrm{e} 5 \mathrm{ebc} \\
\mathrm{a}\end{array}$ & $\begin{array}{l}/ \mathrm{dt} / ? \mathrm{c}= \\
5231\end{array}$ \\
\hline 14 & $\begin{array}{l}10746 \\
28808\end{array}$ & $\begin{array}{l}213.220 \\
194.175\end{array}$ & $\begin{array}{l}680 \mathrm{dd} 76 \\
\text { 69205ae } \\
\text { d163dbb } \\
\text { 06bfd8ec } \\
\text { abd }\end{array}$ & $\begin{array}{l}\text { /findp/p } \\
\text { reber3. } \\
\text { php }\end{array}$ \\
\hline 14 & $\begin{array}{l}10746 \\
28808\end{array}$ & $\begin{array}{l}194.228 \\
166.69\end{array}$ & $\begin{array}{l}\text { a955d38 } \\
\text { c204e57 } \\
2 \text { ab6354 } \\
1817880 \\
6168\end{array}$ & $\begin{array}{l}\text { /ls/preb } \\
\text { er.php }\end{array}$ \\
\hline 10 & $\begin{array}{l}10746 \\
28808\end{array}$ & $\begin{array}{l}62.177 .7 \\
7.138\end{array}$ & $\begin{array}{l}\text { 4e38b17 } \\
\text { a019a39 } \\
\text { 9d01831 } \\
\text { 9e337c3 } \\
\text { 95ad }\end{array}$ & $\begin{array}{l}/ \mathrm{dt} / \text { prisl } \\
\text { php?id } \\
=7578\end{array}$ \\
\hline
\end{tabular}


Selanjutnya dilakukan pre-processing data terhadap data log tersebut. bagian pertama pada tahap pre-processing dilakukan untuk menghasilkan sequence database seperti terlihat pada tabel 3 Sequence Database.

\begin{tabular}{|c|c|}
\hline Session & $\begin{array}{c}\text { Visited } \\
\text { Page }\end{array}$ \\
\hline $\begin{array}{l}\text { 6cf200741ca492c1666b42c0aa879 } \\
377\end{array}$ & / ls \\
\hline $\begin{array}{l}\text { 24675844746d8353d00b2240db2 } \\
\text { cd1ae }\end{array}$ & ls \\
\hline $\begin{array}{l}\text { 69fa610df40c7118aa7912e35155f } \\
762\end{array}$ & $\begin{array}{l}\text { / ct ls dt } \\
\text { ls dt ls } \\
\mathrm{dt} \text { ls dt } \\
\text { ls dt ls } \\
\mathrm{dt} \text { ls dt } \\
\text { ls dt ls }\end{array}$ \\
\hline $\begin{array}{l}\text { ed316ac9b35b4d703920eb43f927 } \\
\text { 90b0 }\end{array}$ & $\mathrm{df} d \mathrm{t}$ \\
\hline $\begin{array}{l}\text { 1e852e124d4aea2cd6c7150a21a5 } \\
\text { 1e94 }\end{array}$ & ls \\
\hline $\begin{array}{l}\text { baef21dc9b744e8d77fb1ce1d0e97 } \\
\text { 7f0 }\end{array}$ & findp \\
\hline $\begin{array}{l}\text { 156bd9732087fcdcaec72376d406 } \\
\text { 1ae4 }\end{array}$ & $\mathrm{dt}$ \\
\hline $\begin{array}{l}\text { e2fec82d4715a294e9540bec8702 } \\
3 \mathrm{fdf}\end{array}$ & $\begin{array}{l}\text { / ct ls dt } \\
\text { ls dt ls } \\
\mathrm{dt} \\
\text { znacka } \\
\mathrm{dt} \text { ls dt } \\
\text { ls dt }\end{array}$ \\
\hline $\begin{array}{l}\text { f22093add2b9dc88d83c1167a0fe0 } \\
37 \mathrm{~b}\end{array}$ & / \\
\hline $\begin{array}{l}\text { 3b3d093e3bd62c1f737fc3a99106f } \\
\text { b66 }\end{array}$ & ls \\
\hline $\begin{array}{l}\text { 8f16c7a4d649f341296d44716f2df } \\
\text { e1c }\end{array}$ & / ct \\
\hline $\begin{array}{l}387 \mathrm{cb} 0078 d 37 a a 354700065 f 2140 \\
\text { dcae }\end{array}$ & $\begin{array}{l}\mathrm{dt} \\
\text { poradna } \\
\mathrm{ct} / \\
\text { findf } \mathrm{dt} \\
\text { findf } \mathrm{dt} \\
\text { findf dt } \\
\text { findf dt } \\
\text { klient }\end{array}$ \\
\hline $\begin{array}{l}\text { f3cc04154ca0cbd73248c0b07aa8e } \\
508\end{array}$ & $\begin{array}{l}\text { / } \\
\text { znacka } \\
\text { / } \\
\text { obchod } \\
\text { y- } \\
\text { elektro } \\
\text { / }\end{array}$ \\
\hline $\begin{array}{l}\text { b55b3a50fc5abcefc339fc1ac0533e } \\
\text { d9 }\end{array}$ & $\begin{array}{l}\text { / ct ls dt } \\
\text { ls dt ls } \\
\mathrm{dt} \text { ls dt }\end{array}$ \\
\hline 642b5bc5f6f20b43e4091f8f8f62bf & poradna \\
\hline
\end{tabular}

\begin{tabular}{|l|l|}
\hline $4 \mathrm{e}$ & \\
\hline $\begin{array}{l}\text { e6332b88864cfe866b319e28f5fe9f } \\
\text { cf }\end{array}$ & znacka \\
\hline & / ct / ls \\
$\begin{array}{l}1561188 c 58329 d 5824 \text { eec0b9f85fd } \\
967\end{array}$ & $\begin{array}{l}\text { dt ls dt } \\
\text { ls dt } \\
\text { znacka }\end{array}$ \\
\hline
\end{tabular}

\subsection{Pattern Discovery WUM}

Pada penelitian ini Teknik mining yang diimplementasi pada tahapan pattern discovery adalah Frequence Sequence Mining. Gambar 5 Hasil Ekstraksi WUM Menggunakan Frequence Sequence Mining dibawah ini adalah hasil pattern discovery WUM menggunakan frequence sequence minig dari data hasil pre-processing pada tahap sebelumnya.

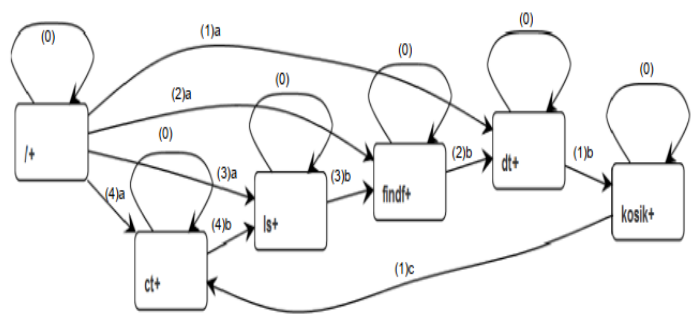

Gambar 6 Hasil Ekstraksi WUM Menggunakan Frequence Sequence Mining

Keterangan :

- 1+: Halaman Home

- ct+: Halaman Kategori Produk

- 1s+: Halaman List Produk

- dt+: Halaman Detil Produk

- findf+: Halaman Pencarian Produk dan Aksesories

- kosik+: Halaman Keranjang Belanja, Proses Check Out.

Sehingga dari urutan-urutan aktivitas pelanggan tersebut pola urutan halaman web e-commerce yang biasa diakses pelanggan adalah Home $\rightarrow$ Home, atau Home $\rightarrow$ Detail Product, atau Home $\rightarrow$ Detail Product $\rightarrow$ Shopping Cart, atau Home $\rightarrow$ Detail Product $\rightarrow$ Shopping Cart $\rightarrow$ Product Category.

\section{Kesimpulan}

\subsection{Kesimpulan}

Hasil ekstraksi click stream data e-commerce pada penelitian ini memanfaatkan Web Usage Mining dengan Teknik mining frequent sequence mining menghasilkan 6 halaman web yang paling sering diakses oleh visitor dengan pola urutan akses yang berbeda-beda. Nilai minimum support yang digunakan sangat mempengaruhi pola halaman akses visitor web e-commerce yang dihasilkan. 


\subsection{Future Works}

Future works dari penelitian ini dengan mengeksplorasi lebih lanjut variable independent yang dianggap sangat mempengaruhi pola yang dihasilkan seperti nilai minimum support agar pola akses visitor e-commerce lebih optimal. Urutan pola akses visitor web e-commerce dapat dimanfaatkan untuk mendukung dalam tahap desain pada pengembangan web e-commerce.

\section{Daftar Pustaka:}

Abdurrahman, T Riyanto, B., Mandala, R., \& Govindaraju, R. (2008). PEMANFAATAN ALGORITMA ANT COLONY UNTUK WEB USAGE MINING. Konferensi Dan Temu Nasional Teknologi Informasi Dan Komunikasi Untuk Indonesia.

Azam, \& Tabrez, N. (2014). Data Mining of Web Access Logs Using Classification Techniques. International Journal For Research in Applied Science Engineering Technology ( I J R A S E T), 2(Viii), 1-5.

Cooley, R. (2000). Web Usage Mining: Discovery and Application of Interesting Patterns from Web Data.

Cooley, R., Mobasher, B., \& Srivastava, J. (1997). Web Mining: Information and Pattern Discovery on the World Wide Web.

Diah, K., \& Yunanto, W. (2017). Heuristics miner for e-commerce visitor access pattern representation. Communications in Science and Technology, 2(1), 1-5. https://doi.org/10.21924/cst.2.1.2017.21

Hamid Mughal, M. J. (2018). Data mining: Web data mining techniques, tools and algorithms: An overview. International Journal of Advanced Computer Science and Applications, 9(6), 208-215. https://doi.org/10.14569/IJACSA.2018.090630

Iváncsy, R., \& Vajk, I. (2006). Frequent pattern mining in web log data. Acta Polytechnica Hungarica, 3(1), 77-90. http://citeseerx.ist.psu.edu/viewdoc/download? doi=10.1.1.101.4559\&amp;rep=rep1\&amp;typ $\mathrm{e}=\mathrm{pdf}$

Mishra, R. (2012). Discovery of Frequent Patterns from Web Log Data by using FP-Growth algorithm for Web Usage Mining. International Journal of Advanced Research in Computer Science and Software Engineering, 2(9), 311-318.

Rathod, D. M. (2012). A Review On Web Mining. International Journal of Engineering Research and Technology (IJERT), Vol. 1(2, April 2012).

Roy, R., \& Appa Rao, G. (2020). Survey on preprocessing web log files in web usage mining. International Journal of Advanced Science and Technology, 29(3 Special Issue), 682-691.

Senkul, Pinar, and S. S. (2012). Improving pattern quality in web usage mining by using semantic information. Knowledge and Information Systems, 30.3, 527-541.

Srivastava, J., Cooley, R., Deshpande, M., \& Tan, P. (2000). Web usage mining: discovery and applications of usage patterns from Web data. ACM SIGKDD Explorations Newsletter, 1223.

Srivastava, J., \& Desikan, Prasanna, Kumar, V. (n.d.). Web Mining - Concepts, Applications, and Research Directions.

Srivastava, J., Desikan, P., \& Kumar, V. (2005). Web Mining - Concepts , Directions. Foundations and Advances in Data Mining Studies in Fuzziness and Soft Computing, 180, 2005, 51-71.

Tatsiopoulos, I. P., Panayiotou, N. A., \& Ponis, S. T. (2002). A modelling and evaluation methodology for E-Commerce enabled BPR. Computers in Industry, 49(1), 107-121. https://doi.org/10.1016/S0166-3615(02)000623

Vellingiri, J;Pandian, S. . (2011). A Survey on Web Usage Mining. Global Journal of Computer Science and Technology, 11(4).

Wang, Y. (2000). Web mining and knowledge discovery of usage patterns. CS $748 T$ Project, Part I, 1-25. https://cs.uwaterloo.ca/ tozsu/courses/cs748t/s urveys/wang.pdf

Wani, K., \& Bakal, J. W. (2014). Association Rule Mining From Server Log File. International Journal on Advanced Computer Theory and Engineering (IJACTE), 6-11.

Wen, H. J., Chen, H. G., \& Hwang, H. G. (2001). Ecommerce Web site design: Strategies and models. Information Management and Computer Security, 9(1), 5-12. https://doi.org/10.1108/09685220110366713 
Volume 7, Edisi 2, Februari 2021

$\mathbf{7 2} \mid \mathrm{H}$ a 1 a $\mathrm{m}$ a $\mathrm{n}$ 